\title{
Congress President
}

\section{ISSHP 2021}

The 22nd World Congress of International Society for the Study of Hypertension in Pregnancy

Date: September 15 (Wed.) to 28 (Tue.), 2021

Virtual On-demand Conference http://isshp2020.umin.jp/

Congress Chair: Shigeru Saito (University of Toyama)

Program: http://isshp2020.umin.jp/program/

\section{JSSHP2021}

The 41st Annual Meeting of the Japan Society for the Study of Hypertension in Pregnancy

Date: December 24 (Fri.) to 25 (Sat.), 2021

Venue: Nara Prefectural Convention Center

Congress Chair: Tomoaki Ikeda (Mie University)

Program: http://isshp2020.umin.jp/jsshp/program/ 


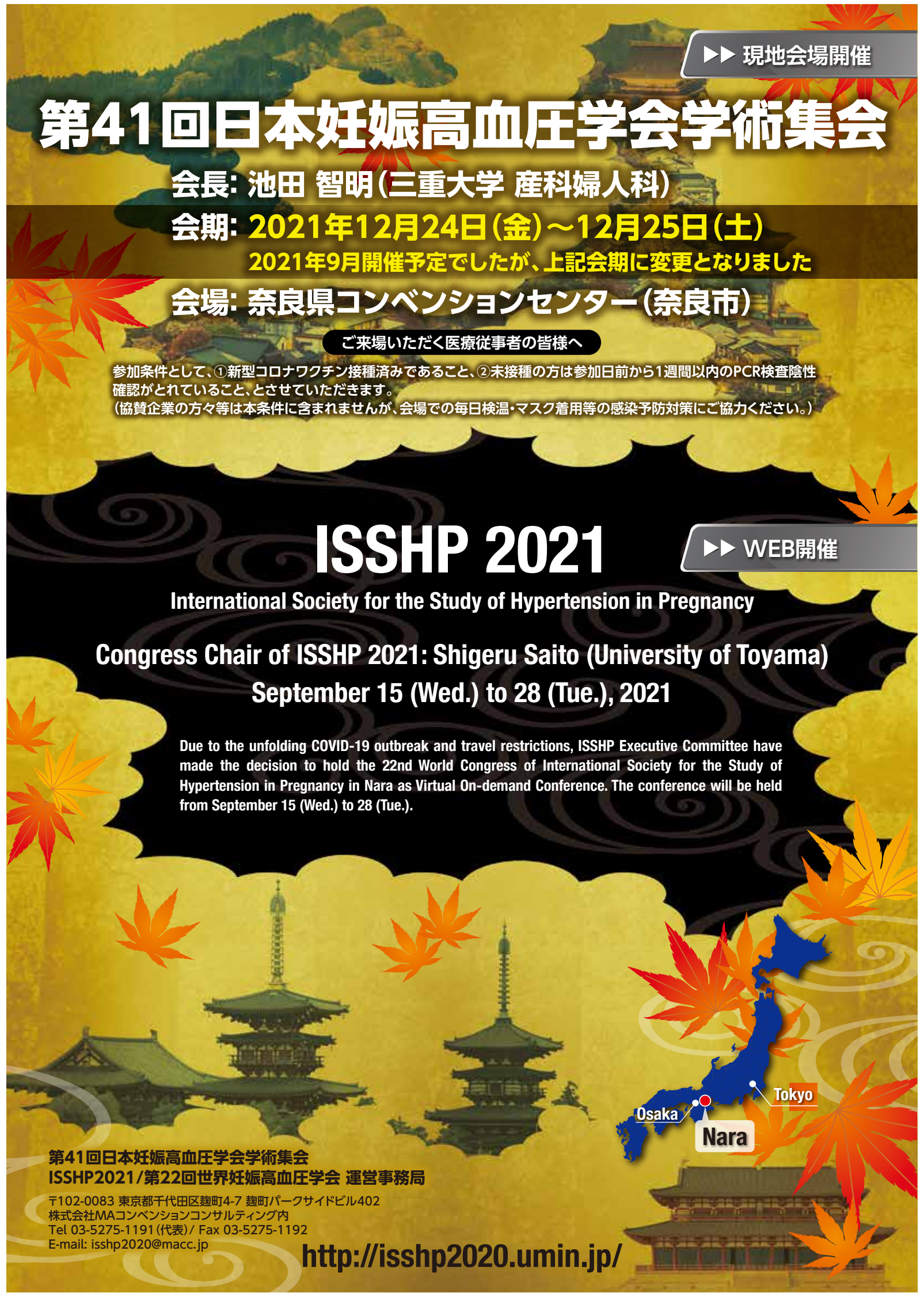

